\title{
INVESTIGATION OF FOSSIL FUEL AND LIQUID BIOFUEL BLEND PROPERTIES USING ARTIFICIAL NEURAL NETWORK
}

\author{
P. Nematizade, B. Ghobadian and G. Najafi \\ Faculty of Agricultural Science, Tarbiat Modares University \\ Jalale_E-Aleahmad Highway, Tehran, Iran \\ Phone: +982144196522, Fax: +9844196524 \\ E-mail: ghobadib@modares.ac.ir
}

\begin{abstract}
Gasoline fuel is the baseline fuel in this research, to which bioethanol, biodiesel and diesel are additives. The fuel blends were prepared based on different volumes and following which, ASTM (American Society for Testing and Materials) test methods analysed some of the important properties of the blends, such as: density, dynamic viscosity, kinematic viscosity and water and sediment. Experimental data were analysed by means of Matlab software. The results obtained from artificial neural network analysis of the data showed that the network with feed forward back propagation of the Levenberg-Marquardt train LM function with 10 neurons in the hidden layer was the best for predicting the parameters, including: Water and sediment $(W)$, dynamic viscosity $(D V)$, kinematic viscosity $(K V)$ and density $(D e)$. The experimental data had a good correlation with ANN-predicted values according to 0.96448 for regression.
\end{abstract}

Keywords: Fossil fuels, biofuels, kinematic viscosity, density, artificial neural network.

\section{INTRODUCTION}

The limited reserves and negative environmental consequences of fossil fuels have spurred on the search for renewable transportation biofuels (Hill et al., 2006). The potential role of alternative renewable fuels in alleviating these environmental concerns is driving the first actions towards the production of a sustainable fuel supply. Biofuels, such as alcohols and biodiesel, are alternatives for internal combustion engines (Hill et al., 2006' Agarwal, 2007). Alternative fuels are those fuels obtained from sources other than oil. Renewability reduced air pollutants and greater economic profits are the main advantages of alternative fuels compared with fossil fuels (Hill et al., 2006). Hitherto, many methods have been used to reduce the environmental pollution associated with fossil fuels, such as engine exhaust emissions; adding oxygenated components to fossil fuels is one of the most important. Among those elements that are used for this purpose, types of alcohol and biodiesel have a high ability to reduce engine exhaust pollutants, due to their lack of sulphur and the presence of oxygen. This is the major advantage of these types of fuel compared with conventional fuels (Hill et al., 2006' Agarwal, 2007). Biodiesel produced from vegetable or animal substances and bioethanol produced from plant materials, have low production costs and are environmentally friendly. 
In relation to spark ignition (SI) engines, this work is done through a combination of alcohol with gasoline. Many investigators have studied the use of ethanol and gasoline blended fuels in SI engines (Kiani Deh Kiani et al., 2010). There are various methods to reduce the exhaust pollution from compression ignition (CI) engines. These methods can be divided into four groups: (i) the diesel-biodiesel fuel blend ((Hill et al., 2006; Agarwal, 2007; Demirbas, 2007; Pourkhesalian et al., 2010), (ii) the diesel-alcohol fuel blend (ethanol or methanol) [1], (iii) the biodieselalcohol fuel blend (ethanol or methanol) (Agarwal, 2007), (iv) diesel-biodieselalcohol fuel blend (Agarwal, 2007; Demirbas, 2007; Pourkhesalian et al., 2010; Tormos et al., 2010).

An experimental study was conducted to characterise some key fuel properties of diesel-biodiesel-bioethanol blends and to evaluate their effects on diesel engine performance. As a result, a new blend called "Diesterol" was developed and used as an alternative fuel (Rahimi et al., 2009). The use of artificial neural networks for modelling the operation of internal combustion engines is a more recent development. This approach was used to predict the performance and exhaust emissions of diesel engines (Agarwal, 2007; Demirbas, 2007; Pourkhesalian et al., 2010) and the specific fuel consumption and fuel-air equivalence ratio of a diesel engine (Agarwal, 2007; Demirbas, 2007). For example, in one study, the effect of gasoline fuel and ethanol-gasoline blends (E5, E10, E15 and E20) on performance and exhaust emissions of an SI engine were investigated using an artificial neural network (ANN). The results showed that using ethanol-gasoline blends increased the power, torque outputs, thermal efficiency and volumetric efficiency. In addition, they also decreased the brake specific fuel consumption (Agarwal, 2007). In another study using ANN to predict the engine brake power, output torque and exhaust emissions $(\mathrm{CO}, \mathrm{CO} 2, \mathrm{NOx}$ and $\mathrm{HC})$, the engine was fuelled with ethanol-gasoline blended fuels with various percentages of ethanol $(0,5,10,15$ and 20\%) and operated at different engine speeds and loads. The results showed that the ANN provided the greatest accuracy in modelling the emission indices (Najafi et al., 2009). In this research, gasoline fuel is the baseline fuel, to which bioethanol, biodiesel and diesel are additives. The fuel blends were prepared based on different volume, following which some of the important properties of the blends were evaluated by following the ASTM test methods. The computer program MATLAB 7.6, neural network toolbox was used for the ANN design.

\section{MATERIALS AND METHODS}

\section{Materials}

The biodiesel fuel used in this study was produced from the transesterification of waste cooking oil with methanol $\left(\mathrm{CH}_{3} \mathrm{OH}\right)$, catalysed by potassium hydroxide $(\mathrm{KOH})$. The important properties of biodiesel were established and compared with the ASTM D6751 standard. The gasoline and diesel used were the conventional fuels in Iran. An Iranian company provided bioethanol with a purity of $99.6 \%$. According to the results of research, mixing bioethanol with gasoline up to $20 \%$ volume, does not create a problem in SI engines and does not require any modification to the engine construction (Agarwal, 2007; Eyidogan et al., 2010). It is a similar situation when using biodiesel-diesel blends in a CI engine (Saravanan et al., 2010; Agarwal, 
2007). Therefore, biodiesel and bioethanol were considered from 5-20\% volume. Similarly, the volume of the diesel fuel was chosen as 5-20\%. Therefore, the percentage volume of the gasoline fuel was determined accordingly. The fuel blends were provided in the ratios as presented in Table 1.

\section{Methods}

This study measured four properties of fuels by following the ASTM test methods. Each test was performed three times using a quite random model. The measured fuel properties were water and sediment, dynamic viscosity, kinematic viscosity and density. Density, dynamic viscosity and kinematic viscosity were measured at $40{ }^{\circ} \mathrm{C}$. The ambient temperature was $29-34{ }^{\circ} \mathrm{C}$. The device used for measuring density, dynamic viscosity and kinematic viscosity was the Anton Paar Stabinger viscometer, model SVM-3000 under ASTM D445 and ASTM D7042-04 standards. This device is able to simultaneously calculate and display density, dynamic viscosity and kinematic viscosity. The device used for measuring water and sediment was a Metrohm Karl Fischer model 794 Basic Titrino under ASTM D2709 standard. Finally, the results were analysed by means of ANN and derived into three sections: training, validation and test.

Table 1. Volume percentage of the test fuel blends

\begin{tabular}{|c|c|c|c|c|c|c|c|c|c|c|c|}
\hline & $\begin{array}{c}\text { Fuel } \\
\text { name }\end{array}$ & Ethanol & Biodiesel & Diesel & Gasoline & & $\begin{array}{c}\text { Fuel } \\
\text { name }\end{array}$ & Ethanol & Biodiesel & Diesel & Gasoline \\
\hline 1 & $\overline{\mathrm{A} 1}$ & 5 & 5 & 5 & 85 & 33 & $\mathrm{C} 1$ & 15 & 5 & 5 & 75 \\
\hline 2 & A2 & 5 & 5 & 10 & 80 & 34 & $\mathrm{C} 2$ & 15 & 5 & 10 & 70 \\
\hline 3 & A3 & 5 & 5 & 15 & 75 & 35 & $\mathrm{C} 3$ & 15 & 5 & 15 & 65 \\
\hline 4 & A4 & 5 & 5 & 20 & 70 & 36 & $\mathrm{C} 4$ & 15 & 5 & 20 & 60 \\
\hline 5 & A5 & 5 & 10 & 5 & 80 & 37 & $\mathrm{C} 5$ & 15 & 10 & 5 & 70 \\
\hline 6 & A6 & 5 & 10 & 10 & 75 & 38 & C6 & 15 & 10 & 10 & 65 \\
\hline 7 & A7 & 5 & 10 & 15 & 70 & 39 & $\mathrm{C} 7$ & 15 & 10 & 15 & 60 \\
\hline 8 & A8 & 5 & 10 & 20 & 65 & 40 & $\mathrm{C} 8$ & 15 & 10 & 20 & 55 \\
\hline 9 & A9 & 5 & 15 & 5 & 75 & 41 & C9 & 15 & 15 & 5 & 65 \\
\hline 10 & A10 & 5 & 15 & 10 & 70 & 42 & $\mathrm{C} 10$ & 15 & 15 & 10 & 60 \\
\hline 11 & A11 & 5 & 15 & 15 & 65 & 43 & $\mathrm{C} 11$ & 15 & 15 & 15 & 55 \\
\hline 12 & A12 & 5 & 15 & 20 & 60 & 44 & $\mathrm{C} 12$ & 15 & 15 & 20 & 50 \\
\hline 13 & A13 & 5 & 20 & 5 & 70 & 45 & $\mathrm{C} 13$ & 15 & 20 & 5 & 60 \\
\hline 14 & A14 & 5 & 20 & 10 & 65 & 46 & $\mathrm{C} 14$ & 15 & 20 & 10 & 55 \\
\hline 15 & A15 & 5 & 20 & 15 & 60 & 47 & C15 & 15 & 20 & 15 & 50 \\
\hline 16 & A16 & 5 & 20 & 20 & 55 & 48 & C16 & 15 & 20 & 20 & 45 \\
\hline 17 & B1 & 10 & 5 & 5 & 80 & 49 & D1 & 20 & 5 & 5 & 70 \\
\hline 18 & B2 & 10 & 5 & 10 & 75 & 50 & D2 & 20 & 5 & 10 & 65 \\
\hline 19 & B3 & 10 & 5 & 15 & 70 & 51 & D3 & 20 & 5 & 15 & 60 \\
\hline 20 & B4 & 10 & 5 & 20 & 65 & 52 & D4 & 20 & 5 & 20 & 55 \\
\hline 21 & B5 & 10 & 10 & 5 & 75 & 53 & D5 & 20 & 10 & 5 & 65 \\
\hline 22 & B6 & 10 & 10 & 10 & 70 & 54 & D6 & 20 & 10 & 10 & 60 \\
\hline 23 & B7 & 10 & 10 & 15 & 65 & 55 & D7 & 20 & 10 & 15 & 55 \\
\hline 24 & B8 & 10 & 10 & 20 & 60 & 56 & D8 & 20 & 10 & 20 & 50 \\
\hline 25 & B9 & 10 & 15 & 5 & 70 & 57 & D9 & 20 & 15 & 5 & 60 \\
\hline 26 & B10 & 10 & 15 & 10 & 65 & 58 & D10 & 20 & 15 & 10 & 55 \\
\hline 27 & B11 & 10 & 15 & 15 & 60 & 59 & D11 & 20 & 15 & 15 & 50 \\
\hline 28 & B12 & 10 & 15 & 20 & 55 & 60 & D12 & 20 & 15 & 20 & 45 \\
\hline 29 & B13 & 10 & 20 & 5 & 65 & 61 & D13 & 20 & 20 & 5 & 55 \\
\hline 30 & B14 & 10 & 20 & 10 & 60 & 62 & D14 & 20 & 20 & 10 & 50 \\
\hline 31 & B15 & 10 & 20 & 15 & 55 & 63 & D15 & 20 & 20 & 15 & 45 \\
\hline 32 & B16 & 10 & 20 & 20 & 50 & 64 & D16 & 20 & 20 & 20 & 40 \\
\hline
\end{tabular}




\section{RESULTS AND DISCUSSION}

\section{Artificial Neural Network}

MATLAB software was used to analyse the results with ANN. At first, different networks with a variable number of layers that are explanatory of network volume were used for modelling input data. The number of repeats at the training stage of each network represents the convergence speed of that network and can be considered as the model optimisation parameter. In addition, the training error was considered as the third criterion of network performance. Accordingly, the networks with two layers (a hidden layer and an output layer) were designed for predictions. The feed forward back propagation method was used with different training functions and data derived into three sections: training, validation and test. Mean Square Error (MSE) is the network error criterion. Water and sediment $(W)$, dynamic viscosity $(D V)$, kinematic viscosity $(K V)$ and density $(D e)$ were selected as neurons of the output layer. The input layer had three neurons including bioethanol $(E)$, biodiesel $(B)$ and diesel $(D)$. The neuron number of the hidden layer was varied between 5 and 20. Thus, the best network for predicting $W$ (Water and sediment), $D V$ (dynamic viscosity), $K V$ (kinematic viscosity) and $D e$ (density) was selected by means of changing the hidden layer neurons and training functions (Figure 1).

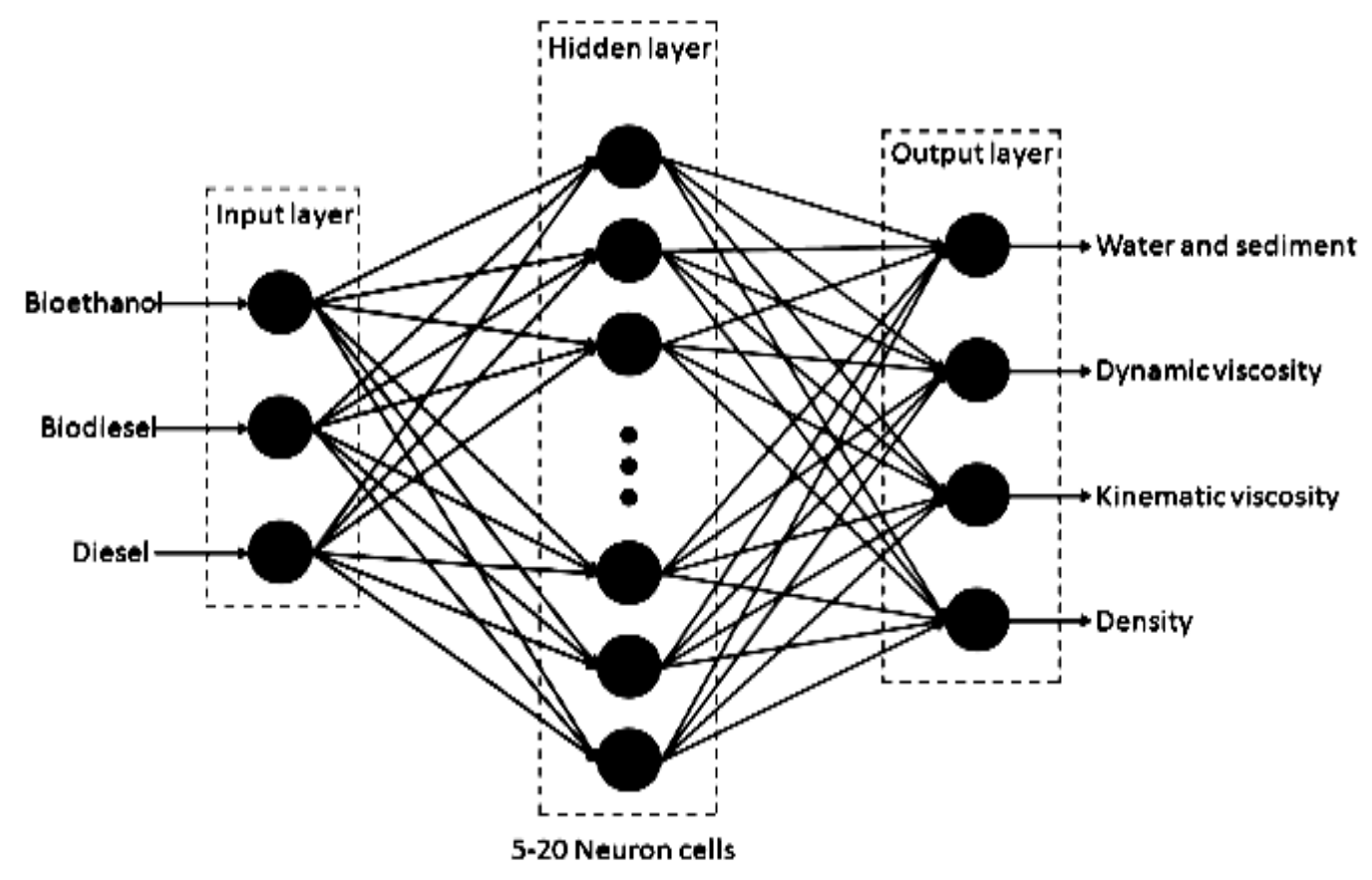

Figure 1. Selected ANN structure.

The results of using different training functions and changing the number of hidden neurons are presented in Table 2. According to Table 2 and the comparison of the regression and training error (RMSE) for functions with different neurons, the network with feed forward back propagation of the Levenberg-Marquardt train LM and 10 neurons in the hidden layer, is the best for predicting the parameters $W, D V$, $K V$ and $D e$. This is because this function has the highest regression, 0.96448 and the 
lowest RMSE, 0.002742 compared with the other functions. Targets are experimental data and outputs are ANN-predicted values.

\section{Network Performance}

Figure 2 shows the performance of the designed network for $W, D V, K V$ and $D e$. As can be seen, the RMSE has acceptably decreased per five repeats of network. The value of the RMSE was 0.002742 , which is close to zero. Hence, confirming the ability of modeling the data. Figure 3 shows the regression analysis of network training, validation and testing between targets and outputs. As can be seen, the regression values for the quadruplet curves of target training, validation and testing all had a good correlation with the outputs.

Table 2. Regression coefficient and train error results using artificial neural network.

\begin{tabular}{|c|c|c|c|c|c|c|c|c|c|c|c|c|}
\hline \multirow{3}{*}{ Train function } & \multicolumn{12}{|c|}{ Neuron number } \\
\hline & \multicolumn{3}{|c|}{5} & \multicolumn{3}{|c|}{10} & \multicolumn{3}{|c|}{15} & \multicolumn{3}{|c|}{20} \\
\hline & $\mathbf{R}$ & RMSE & epochs & $\mathbf{R}$ & RMSE & epochs & $\mathbf{R}$ & RMSE & epochs & $\mathbf{R}$ & RMSE & epochs \\
\hline $\mathrm{b}$ & 0.68772 & 0.025416 & 1000 & 0.67128 & 0.039016 & 1000 & 0.67463 & 0.052467 & 1000 & 0.58093 & 0.078199 & 1000 \\
\hline bfg & 0.948 & 0.002842 & 67 & 0.94543 & 0.006966 & 55 & 0.94926 & 0.0015 & 50 & 0.94963 & 0.004161 & 52 \\
\hline br & 0.95875 & 0.56664 & 8 & 0.96006 & 0.13066 & 14 & 0.95962 & 0.28122 & 7 & 0.95777 & 0.26813 & 8 \\
\hline $\mathrm{c}$ & 0.88693 & 0.38698 & 0 & 0.91334 & 0.61121 & 0 & 0.92961 & 0.79613 & 0 & 0.92176 & 1.5753 & 0 \\
\hline $\operatorname{cgb}$ & 0.95461 & 0.003057 & 32 & 0.92067 & 0.007193 & 15 & 0.94795 & 0.008231 & 28 & 0.95567 & 0.009037 & 39 \\
\hline $\operatorname{cgf}$ & 0.94815 & 0.002877 & 32 & 0.94869 & 0.006924 & 36 & 0.94904 & 0.001524 & 31 & 0.94872 & 0.004204 & 35 \\
\hline cgp & 0.95439 & 0.007207 & 37 & 0.94776 & 0.003726 & 28 & 0.95288 & 0.004185 & 41 & 0.95974 & 0.003773 & 45 \\
\hline $\mathrm{gd}$ & 0.55333 & 0.0364 & 1000 & 0.4682 & 0.050468 & 1000 & 0.40908 & 0.10095 & 1000 & 0.51021 & 0.084198 & 1000 \\
\hline gda & 0.92395 & 0.016214 & 159 & 0.92268 & 0.010753 & 150 & 0.88888 & 0.012284 & 144 & 0.91674 & 0.006875 & 181 \\
\hline gdm & 0.40091 & 0.060291 & 1000 & 0.42258 & 0.086986 & 1000 & 0.47041 & 0.06545 & 1000 & 0.49775 & 0.12455 & 1000 \\
\hline $\operatorname{gdx}$ & 0.95189 & 0.004608 & 193 & 0.95087 & 0.004634 & 204 & 0.95409 & 0.003389 & 182 & 0.94664 & 0.005799 & 177 \\
\hline $\operatorname{lm}$ & 0.96135 & 0.002856 & 10 & 0.96448 & 0.002742 & 7 & 0.95416 & 0.002918 & 3 & 0.95085 & 0.002414 & 3 \\
\hline oss & 0.85438 & 0.01099 & 13 & 0.94708 & 0.004284 & 66 & 0.91998 & 0.004179 & 44 & 0.90694 & 0.013494 & 29 \\
\hline $\mathrm{r}$ & 0.86755 & 0.2377 & 0 & 0.93036 & 0.6687 & 0 & 0.9314 & 0.75671 & 0 & 0.9296 & 2.2849 & 0 \\
\hline $\mathrm{rp}$ & 0.95506 & 0.003636 & 211 & 0.95043 & 0.008296 & 66 & 0.92142 & 0.012686 & 44 & 0.95174 & 0.006466 & 96 \\
\hline scg & 0.95523 & 0.007009 & 40 & 0.94546 & 0.00426 & 31 & 0.95654 & 0.004078 & 89 & 0.93983 & 0.00814 & 22 \\
\hline
\end{tabular}

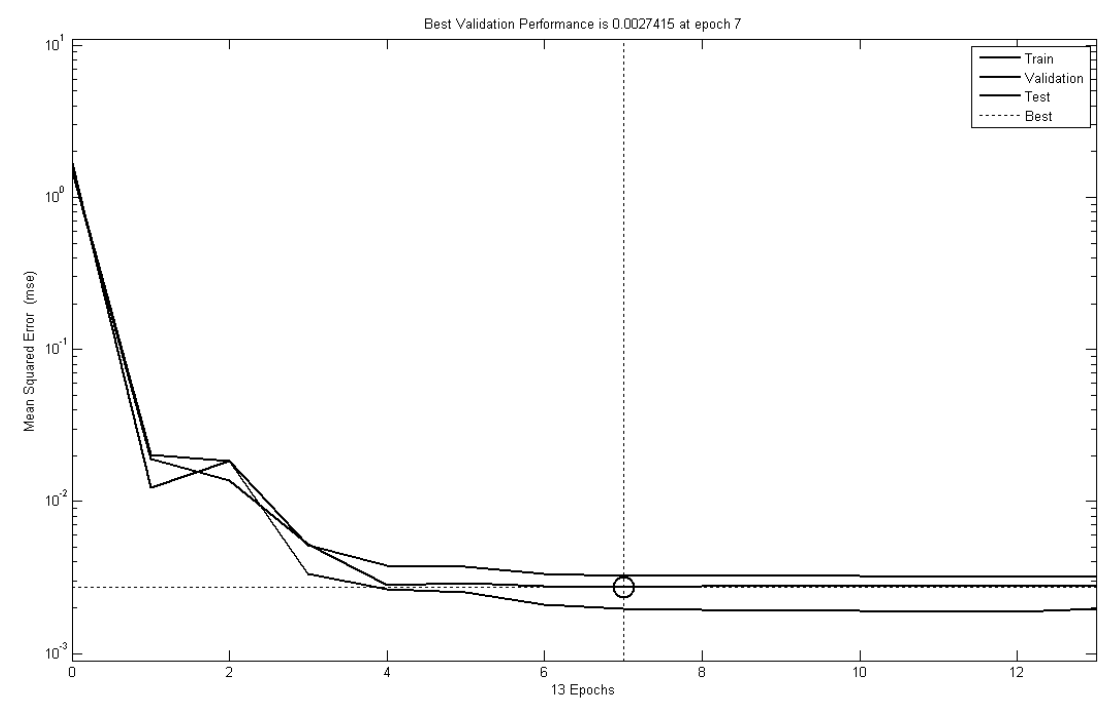

Figure 2. Training network performance diagram for $W, D V, K V$ and $D e$. 


\section{Experimental Data and Predicted Values}

To show the agreement between outputs and targets, this data was plotted on charts (Figures 4-6). According to the regression of targets and outputs, it can be seen that the selected network gives a good performance (Figure 4). It is able to predict the amount of water and sediment, dynemic viscosity, kinematic viscosity and density with low errors $(\mathrm{R}=0.96448)$. For further consideration of this network performance, the comparison of regression was done between targets and outputs of each parameter (Figure 5). The regression values are listed in this figure. Figure 6 illustrates the results of the comparison of outputs and targets in red and blue colours. As can be seen, the outputs for $D V, K V$ and $D e$ have a very good agreement with their targets. However, there is no such accord between the outputs and targets for $W$. The best agreement compared with the other networks was that of the training network with $1 \mathrm{~m}$ function and 10 neurons in the hidden layer.
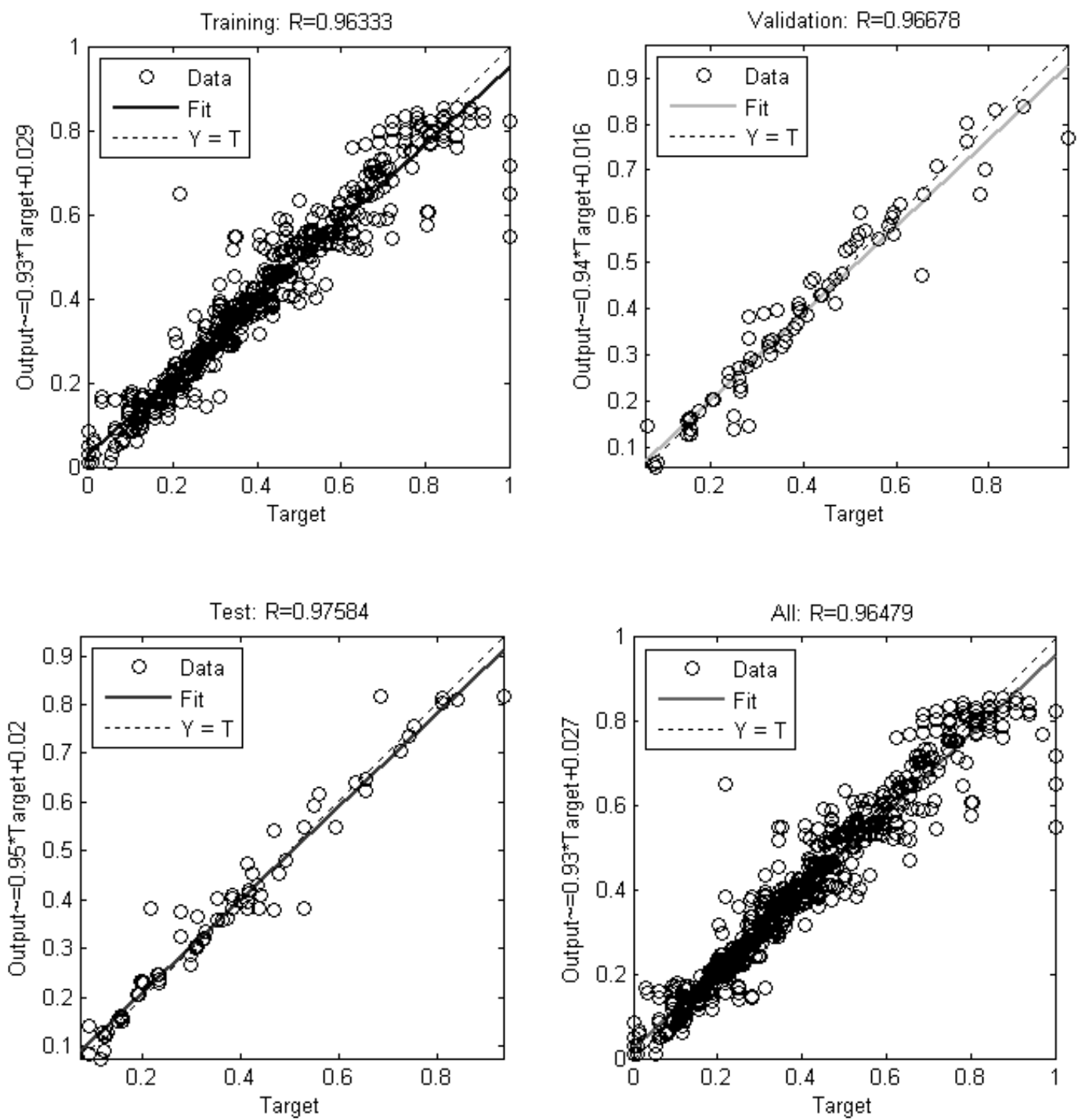

Figure 3. Regression analysis of network training, validation and test between targets and outputs. 


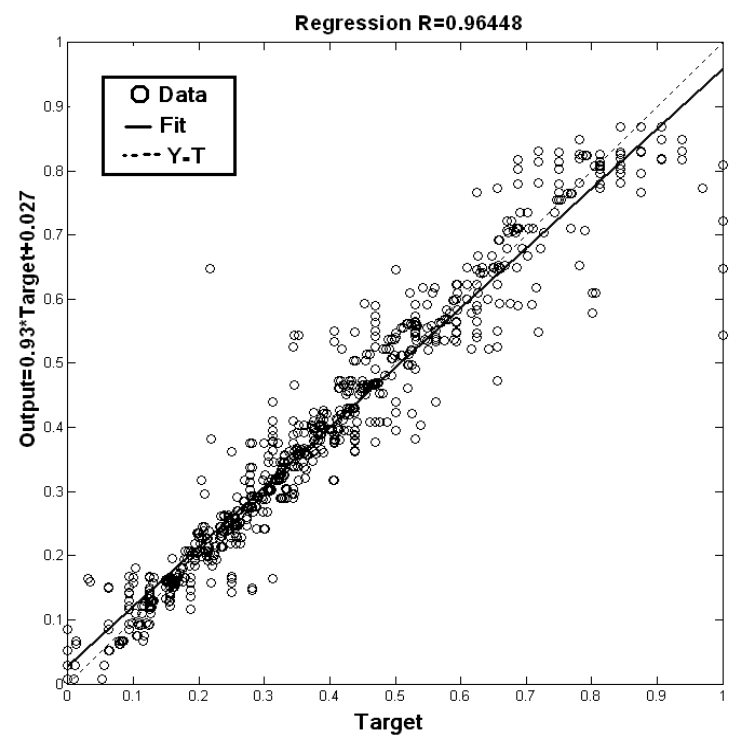

Figure 4. Regression graphic between ANN-predicted values and experimental data.

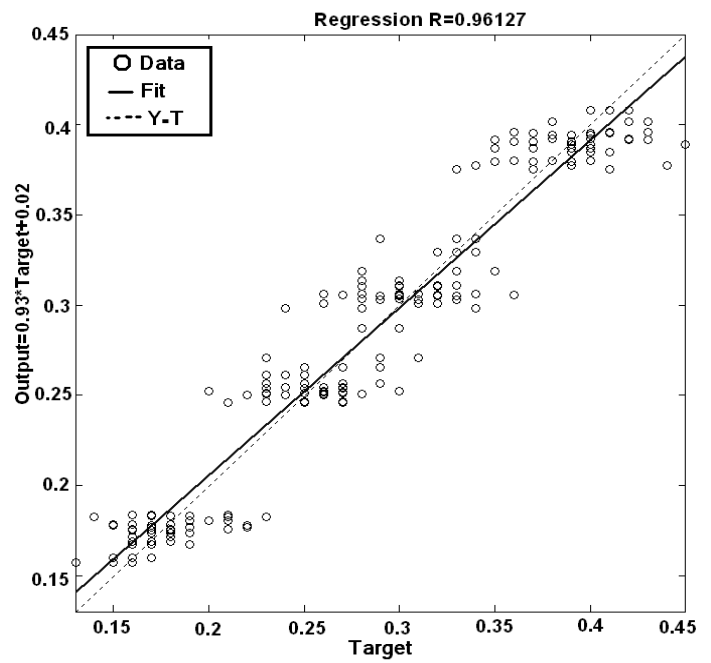

(a) Water and sediment

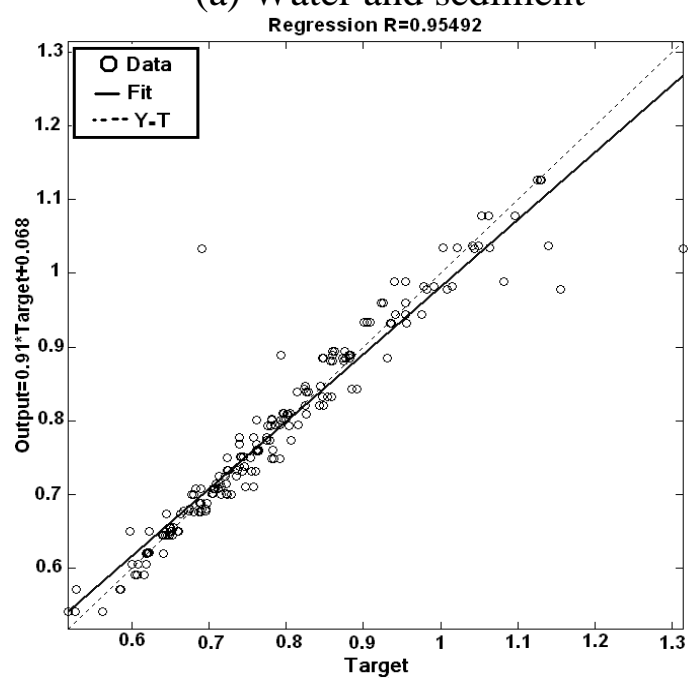

(c) Kinematic viscosity

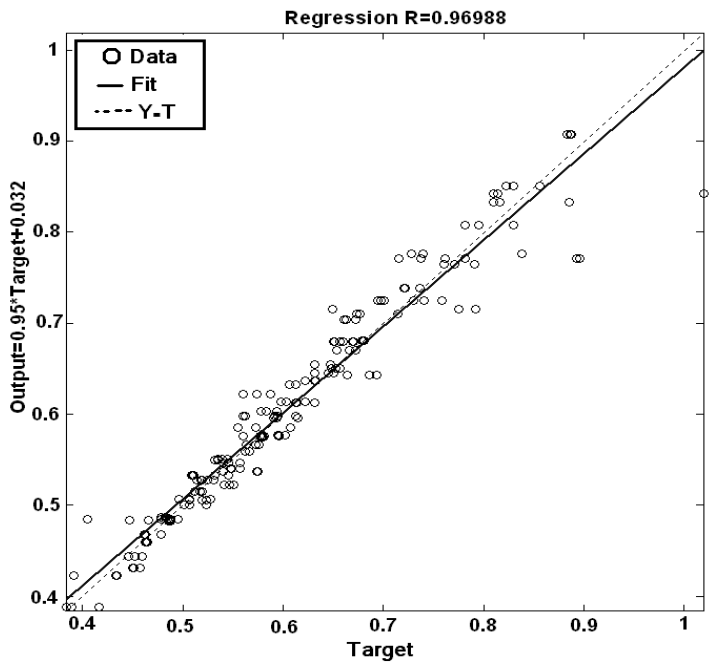

(b) Dynamic viscosity

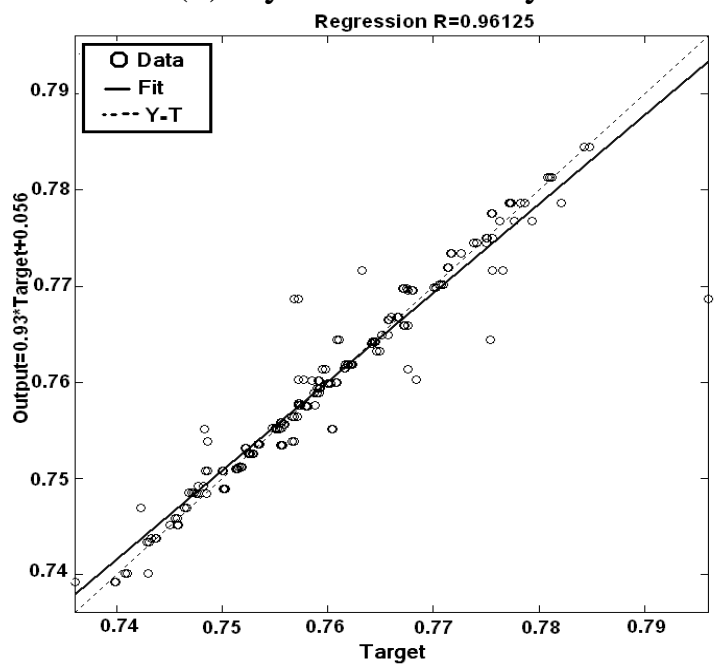

(d) Density

Figure 5. Regression graphic between ANN-predicted values and experimental data. 

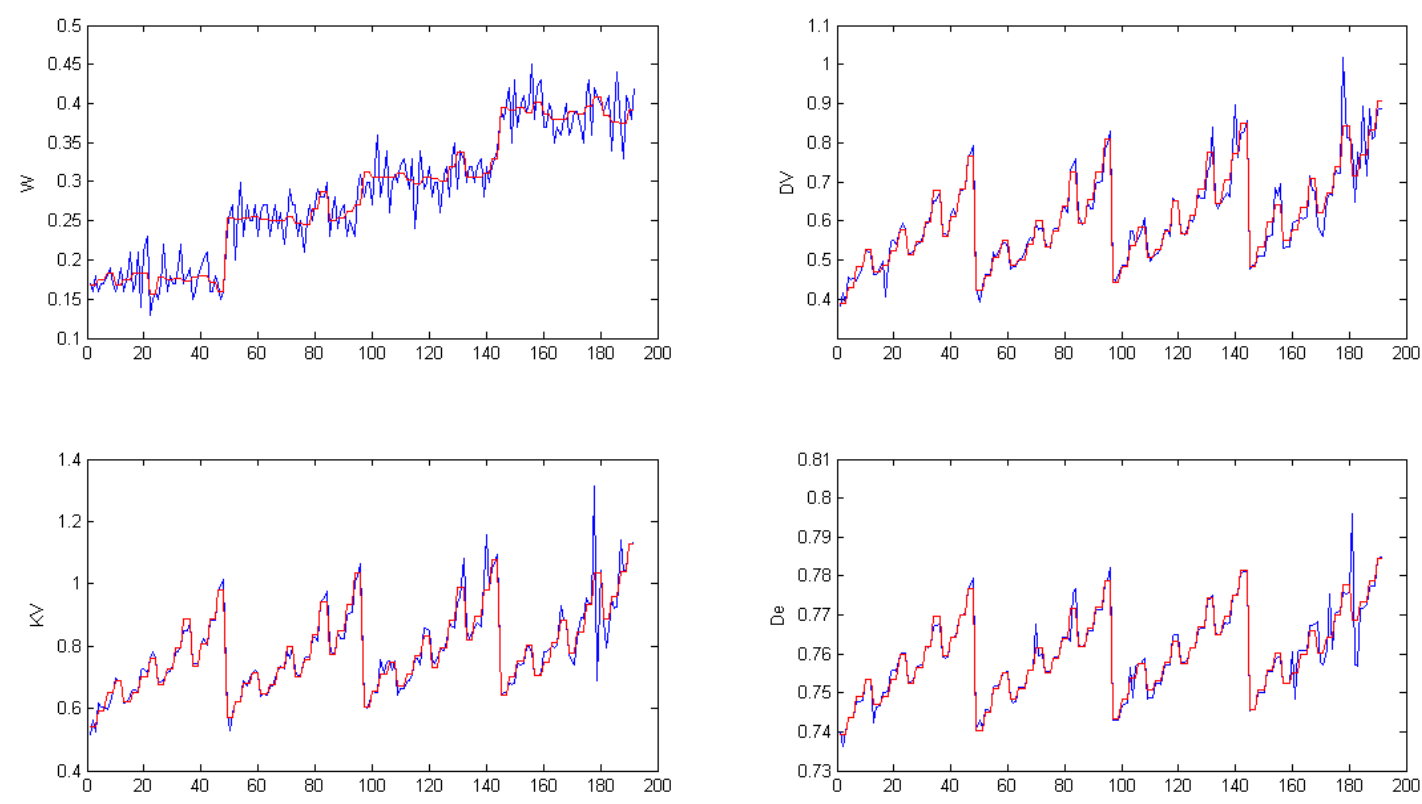

Figure 6. Comparison of ANN-predicted values and experimental data.

\section{CONCLUSION}

This study can be summarised as follows:

1. The network with feed forward back propagation of Levenberg-Marquardt train LM and 10 neurons in the hidden layer was the best for predicting the parameters, including: $W, D V, K V$ and $D e$.

2. The experimental data had a good correlation with the ANN-predicted values according to a regression of 0.96448 . In addition, the regression for each of the experimental parameters $(W, D V, K V$, and $D e)$ was very close to 1 .

3. This network is able to predict reasonably accurately the $W, D V, K V$, and $D e$.

\section{REFERENCES}

Agarwal, A.K. 2007. Biofuels (alcohols and biodiesel) applications as fuels for internal combustion engines. Progress in Energy and Combustion Science, 33(3): 233-271.

Alptekin, E. and Canakci, M. 2008. Determination of the density and the viscosities of biodiesel-diesel fuel blends. Renewable Energy, 33(12): 2623-2630.

Alptekin, E. and Canakci, M. 2009. Characterization of the key fuel properties of methyl ester-diesel fuel blends. Fuel, 88(1): 75-80.

Demirbas, A. 2007. Progress and recent trends in biofuels. Prog Energy Combust Sci, 33(1): 1-18.

Eyidogan, M., Ozsezen, A.N., Canakci, M. and Turkcan, A. 2010. Impact of alcoholgasoline fuel blends on the performance and combustion characteristics of an SI engine. Fuel, 89(10): 2713-2720. 
Hill, J., Nelson, E., Tilman, D., Polasky, S. and Tiffany, D. 2006. Environmental, economic, and energetic costs and benefits of biodiesel and ethanol biofuels. Proceedings of the National Academy of Sciences, 103(30): 11206-11210.

Kiani Deh Kiani, M., Ghobadian, B., Tavakoli, T., Nikbakht, A.M. and Najafi, G. 2010. Application of artificial neural networks for the prediction of performance and exhaust emissions in SI engine using ethanol- gasoline blends. Energy, 35(1): 65-69.

Najafi, G., Ghobadian, B., Tavakoli, T., Buttsworth, D.R., Yusaf, T.F. and Faizollahnejad, M. 2009. Performance and exhaust emissions of a gasoline engine with ethanol blended gasoline fuels using artificial neural network. Applied Energy, 86(5): 630-639.

Pourkhesalian, A.M., Shamekhi, A.H. and Salimi, F. 2010. Alternative fuel and gasoline in an SI engine: A comparative study of performance and emissions characteristics. Fuel, 89(5): 1056-1063.

Rahimi, H., Ghobadian, B., Yusaf, T., Najafi, G. and Khatamifar, M. 2009. Diesterol: An environment-friendly IC engine fuel. Renewable Energy, 34(1): 335-342.

Saravanan, N., Nagarajan, G. and Puhan, S. 2010. Experimental investigation on a DI diesel engine fuelled with Madhuca Indica ester and diesel blend. Biomass and Bioenergy, 34(6): 838-843.

Tormos, B., Novella, R., Garcia, A. and Gargar, K. 2010. Comprehensive study of biodiesel fuel for HSDI engines in conventional and low temperature combustion conditions. Renewable Energy, 35(2): 368-378.

Turrio-Baldassarri, L., Battistelli, C.L., Conti, L., Crebelli, R., De Berardis, B., Iamiceli, A.L., Gambino, M. and Innaccone, S. 2004. Emission comparison of urban bus engine fueled with diesel oil and 'biodiesel' blend. Science of the Total Environment, 327(1-3): 147-162.

Zhu, L., Zhang, W., Liu, W. and Huang, Z. 2010. Experimental study on particulate and NOx emissions of a diesel engine fueled with ultra-low sulfur diesel, RME-diesel blends and PME-diesel blends. Science of the Total Environment, 408(5): 1050-1058. 